\title{
Detective work
}

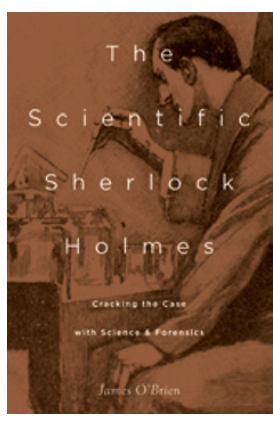

show in the television programme NCIS, the romantic allure of James Bond, or the .44 Magnum of Dirty Harry, Sherlock Holmes has remained one of the most recognized and admired crime-fighting characters for more than 125 years.

O'Brien highlights many parallels between Holmes's forensic techniques and real-world events. In The Beryl Coronet, for instance, Holmes establishes the height, movements and actions of a suspect from crime-scene footprints - reminiscent of the evidence presented in the trial of O. J. Simpson. The unique 'signature' of a typewriter, used to detect the common origin of several letters that a client receives in A Case of Identity, was also a damning piece of evidence against Alger Hiss in his 1950 perjury trial. Holmes uses an Arnold cipher (named after the method that Benedict Arnold used to send coded messages to the British during the American Revolution) in The Valley of Fear to correspond with a secret informant. O'Brien's descriptive stories are long enough to supply relevant literary and historical details, yet sufficiently short to keep the overarching narrative varied and interesting.

An entire chapter is dedicated to Sherlock Holmes the chemist. O'Brien's instructive tone (he is a distinguished professor emeritus of chemistry at Missouri State University) implies that he is writing for a general audience eager to learn about the science behind the Holmes stories. In a series of vignettes reminiscent of Le Couteur and Burreson's Napoleon's Buttons: 17 Molecules that Changed History, O'Brien chronicles the background, chemical structure and societal impact of several substances that appear in the Holmes stories. The topics are wide-ranging (including Julius Caesar, acetone and counterfeit coins) but informative and entertaining. From coal-tar and dyes to chemical poisons and chloroform, there is a wealth of fascinating information for scientific experts and non-experts alike. Admirers of 'back of the envelope' calculations will particularly appreciate the equations accompanying the section about Holmes discovering the deceased butler in The Musgrave Ritual. The unfortunate man had died of $\mathrm{CO}_{2}$ poisoning in an airtight secret chamber. O'Brien's stepwise estimates clearly demonstrate - considering the dimensions of the room, partial pressure of oxygen in the atmosphere at a summertime temperature, and the average rate of human respiration - that Holmes's declaration of the butler having been dead for "some days" is quantitatively accurate. This chapter also confronts the accusation by Isaac Asimov (who himself was a Holmes enthusiast and professor of biochemistry) that the detective was a "blundering chemist" who made multiple errors in nomenclature. Holmes once refers to a blue gemstone as a carbuncle, for example, and a mercury-free alloy as an amalgam. O'Brien provides context for these apparent inaccuracies, mostly defending the detective with additional historical and linguistic evidence, but does, on occasion, side with Asimov.

\section{From coal-tar and dyes to chemical poisons and chloroform, there is a wealth of fascinating information.}

The book concludes with a broad survey of other sciences that play a role in the Holmes series, including mathematics, biology, physics and astronomy. Unlike the archetypal detective equipment that did not appear in Conan Doyle's writing (such as the deerstalker hat and calabash pipe), the magnifying glass was a key tool that Holmes used quite frequently to find clues. His appreciation for optics apparently grew, as he uses a microscope in the final story of the canon, presaging the utility of this basic instrument of modern forensic science.

The Scientific Sherlock Holmes is effective as an accessible yet rigorous examination of the science behind many of Holmes's cases. The content occasionally feels repetitive or loosely organized, but it is also comprehensive and well researched. O'Brien's footnotes and extensive bibliographic citations reveal his considerable expertise and care in writing. Certain passages - like the inventory of all works in which fingerprints are mentioned but unrelated to solving the crime can seem superfluous, but are certainly forgivable. The most fitting homage to a master detective (and scientist), after all, is to leave no detail unexamined.

\section{REVIEWED BY PAUL BONVALLET}

Paul Bonvallet is an associate professor of organic chemistry at the College of Wooster in Ohio, USA. 